\title{
Adiabatic Temperature Rise Test of Cemented Sand and Gravel (CSG) and Its Application to Temperature Stress Prediction of CSG Dam
}

\author{
Minmin Jiang $\mathbb{D}^{1},{ }^{1}$ Xin Cai $\mathbb{D}^{1,2}$ Xingwen Guo $\mathbb{D}^{1},{ }^{2}$ Qinghui Liu, ${ }^{2}$ and Tianye Zhang ${ }^{1}$ \\ ${ }^{1}$ College of Water Conservancy and Hydropower Engineering, Hohai University, Nanjing 210098, China \\ ${ }^{2}$ College of Mechanics and Materials, Hohai University, Nanjing 210098, China \\ Correspondence should be addressed to Xin Cai; xcai@hhu.edu.cn
}

Received 8 January 2020; Accepted 9 June 2020; Published 6 July 2020

Academic Editor: Akbar Heidarzadeh

Copyright (C) 2020 Minmin Jiang et al. This is an open access article distributed under the Creative Commons Attribution License, which permits unrestricted use, distribution, and reproduction in any medium, provided the original work is properly cited.

\begin{abstract}
An adiabatic temperature rise test of cemented sand and gravel (CSG) is conducted, a model for temperature rising of CSG is proposed, and its application to temperature stress prediction of CSG dam is presented. Adiabatic temperature rise tests are first conducted to investigate the temperature rise properties of CSG material with different cementing agent contents. The results demonstrate that the hydration reaction time is longer for CSG material with higher cementing agent content, and a linear relationship is presented between cementing agent contents and final value of adiabatic temperature rise. Then, a calculation model considering different cementing agent contents is developed based on the regression analysis of the test data. The proposed model is implanted into the ANSYS software platform for predictions of temperature distributions and stress fields of a typical CSG dam. The results show that the distributions of temperature and temperature stress are similar to those of roller compacted concrete (RCC) dam. Due to the high temperature stress at the long intermittent surface and downstream surface of the dam, the thermal insulation measures on the surface of the dam should be considered in the CSG dam with high cementing agent contents and in the severe cold environment. Therefore, it cannot be generally considered that the temperature control of the CSG dam does not need to be considered, and it should be determined according to the specific working conditions.
\end{abstract}

\section{Introduction}

Combining with the face slab dam and the roller compacted concrete (RCC) gravity dam, cemented sand and gravel (CSG) dam was first proposed by Raphael [1] at the Conference on Rapid Construction of Concrete in 1970s. Due to its advantages of convenient and fast construction, being economical, and environment-friendly availability [2], the CSGs dam consisting of sand and gravel, a small amount of cementitious materials (cement, fly ash, etc.), and water [3] are being widely used [4], and more than 50 CSG dams and cofferdams have been constructed worldwide [5]. So far, the construction of CSG dam mainly depends on engineering experiences from the earth-rock dams and RCC dams, which is obviously inaccurate. Previous studies [2] showed that the thermal stress of CSG dams may not be high because of their low cementing agent content and low hydration reaction heat. However, with the acceleration of casting speed and dam height, temperature stress cannot be neglected anymore. Moreover, the CSG dam has the risk of cracking due to its low tensile strength.

There is a considerable amount of literature about extensive thermal performance tests and temperature control crack prevention on ordinary concrete [6-9], RCC $[10,11]$, rockfill concrete [12], and other materials. The investigations for the CSG materials are mainly focused on the relevant mechanical properties [13-17], while the impact of adiabatic temperature rise on the CSG material is not fully understood. In terms of experimental investigations, adiabatic temperature rise measurements and field observations of CSG materials are carried out in the literature $[18,19]$. The results showed that the adiabatic temperature rise was $5.2^{\circ} \mathrm{C}$ after $28 \mathrm{~d}$, and the on-site maximum temperature rise of the investigated dam was 
between $4.1^{\circ} \mathrm{C}$ and $6.4^{\circ} \mathrm{C}$. Sun [20] and Sun and Guo [21] conducted a comprehensive study on the adiabatic temperature rise test of CSG material and summarized the influences of cement content, water-binder ratio, admixture content, and other factors on the adiabatic temperature rise rule. At the same time, a series of thermal parameters were measured to provide reference for the follow-up engineering. Guo et al. [22] and Liu [23] proposed an adiabatic temperature rise model for CSG material using adiabatic temperature rise test data.

For numerical simulation, the earliest scholars mainly studied the hardfill dam, which is consistent with the composition material of CSG dam. He et al. [24] and He and Peng [25] conducted temperature field simulation analysis for hardfill, which is a kind of cement content lower than RCC. It is concluded that the highest temperature of hardfill is much lower than that of RCC, which can meet the conditions of accelerating construction speed and has a large anticrack margin. Since then, hardfill has become a new type of dam material. For CSG dam, Wang [26] and Sun and Guo [21] simulated the temperature stress of the Shoukoubu dam with parameters obtained from tests. It is confirmed that the dam still has the risk of cracking owing to the large temperature difference between the inside and the surface of the dam. Gurdil and Batmaz [27] determined the distance between transverse shrinkage joints of CSG dams and showed that no additional thermal cracks would be formed even in hot seasons. $\mathrm{Wu}$ et al. [28] suggested that temperature control measure in construction can be simplified according to the material characteristics and construction technology of CSG.

Although various adiabatic temperature rise tests and numerical calculations have been carried out for CSG material, only a few scholars have tried to obtain adiabatic temperature rise models suitable for CSG material. As the obtained model is relatively single and cannot reflect the real work conditions of CSG material with different cementing agent content, it has little reference significance for subsequent projects, and there are also inaccurate predictions on the change process of temperature field and stress field of CSG dam. In this paper, adiabatic temperature rise test is carried out for CSG materials with different cementing agent contents, and adiabatic temperature rise model suitable for CSG dam is established. On this basis, a finite element method is established to calculate the temperature and stress fields of a typical dam located in China and discuss whether the temperature control measures should be considered for the CSG dam.

\section{Adiabatic Temperature Rise Test of CSG Material}

2.1. Materials and Grouping. According to the technical guidelines for cemented granular material dams [18], the CSG material in this test is composed of P.C. 42.5 ordinary Portland cement, grade I fly ash, stones, sand, and water mixed in proportion. The cement and fly ash are produced by Hailuo Cement Co., Ltd. in Anhui Province, China. The medium coarse sand obtained from the Nanjing market is used as fine aggregate, and cobblestones found in the suburbs of Nanjing are used as coarse aggregates with gradation shown in Table 1.
TABLE 1: Coarse aggregate gradation.

\begin{tabular}{lcccc}
\hline Particle size (mm) & $20-40$ & $10-20$ & $5-10$ & $1-5$ \\
\hline Gradation (\%) & 42.8 & 26.6 & 19.8 & 10.5 \\
\hline
\end{tabular}

The cementing agent content of CSG material is between values for rockfill (cementing agent content is $0 \mathrm{~kg} / \mathrm{m}^{3}$ ) and the roller compacted concrete (cementing agent content is more than $140 \mathrm{~kg} / \mathrm{m}^{3}$ ). The adiabatic temperature rise test is divided into 6 groups according to different cementing agent content of $40,60,80,100,120$, and $140 \mathrm{~kg} / \mathrm{m}^{3}$. The cement and fly ash of the samples are matched by $1: 1$, the water-binder ratio is also $1: 1$, and no admixture is added. The density of specimens is controlled as $2360 \mathrm{~kg} / \mathrm{m}^{3}$, and the content of the composition materials of the six groups is shown in Table 2 .

2.2. Specimen Preparation and Test Instruments. To reduce the variations of mechanical properties, all specimens of each group are poured at once. Due to the large amount of stirring, a medium-sized mixer with a maximum stirring volume of $0.4 \mathrm{~m}^{3}$ is adopted to eliminate the human interference. Firstly, the coarse aggregate and sand were weighed according to the mix proportion and aggregate gradation and then evenly stirred, after which the weighed cement and fly ash were poured and evenly mixed with the premixed gravel. Thereafter, add half of the designed water and stir for 30 seconds. Finally, add the other half of water and stir for 30 seconds. The whole mixing process is presented in Figure 1.

In this test, the adiabatic temperature rise of CSG material is directly measured by IMJR-500 concrete adiabatic temperature rise tester, which is composed of adiabatic temperature rise box and a measurement and control recorder. The adiabatic temperature rise box is mainly composed of concrete container and heater. The working principle diagram is shown in Figure 2. The adiabatic temperature rise box is required to meet the adiabatic test conditions. That is to say, heat generated by the hydration of cementitious materials is not allowed to be transferred to the external environment.

2.3. Adiabatic Temperature Rise Test. Before the test, check whether the difference between the temperatures of adiabatic room and tracking test center exceeds $0.1^{\circ} \mathrm{C}$. The main method is to fill the container with water $25-30^{\circ} \mathrm{C}$ higher than room temperature and level up to $2 \mathrm{~cm}$ from the top of the container. Then the test was carried out in the heat adiabatic room of the container. If the water temperature remains constant, it means that the instrument is normal and the test can be started. Meanwhile, the prepared mixtures were placed in a greenhouse where the room temperature was maintained at $20^{\circ} \mathrm{C}$ for 24 hours.

Formal test operations begin after these preparations are completed. First, mix the CSG material according to Section 2.2, measure the temperature of the mixture, and put it into the container with two batches; vibrate for 30 seconds when each batch is loaded as shown in Figure 3(a). At the same time, a temperature measuring tube shown in Figure 3(b) is inserted 
TABLE 2: Proportions of cementitious material.

\begin{tabular}{lccccc}
\hline Group & Cement $\left(\mathrm{kg} / \mathrm{m}^{3}\right)$ & Fly ash $\left(\mathrm{kg} / \mathrm{m}^{3}\right)$ & Water $\left(\mathrm{kg} / \mathrm{m}^{3}\right)$ & Fine aggregate $\left(\mathrm{kg} / \mathrm{m}^{3}\right)$ & Coarse aggregate $\left(\mathrm{kg} / \mathrm{m}^{3}\right)$ \\
\hline 1 & 20 & 20 & 40 & 570 & 1710 \\
2 & 30 & 30 & 60 & 560 & 1680 \\
3 & 40 & 40 & 80 & 550 & 1650 \\
4 & 50 & 50 & 100 & 540 & 1620 \\
5 & 60 & 60 & 120 & 530 & 1590 \\
6 & 70 & 70 & 140 & 520 & 1560 \\
\hline
\end{tabular}

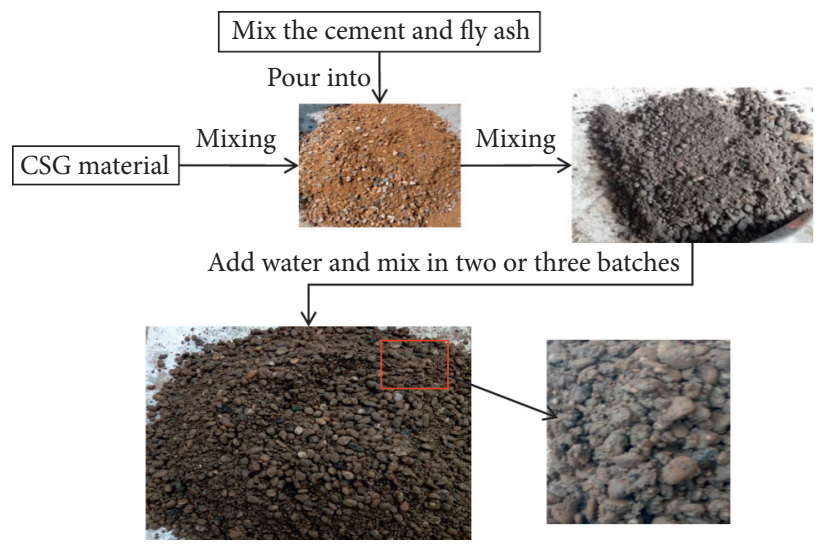

FIGURE 1: CSG material mixing process.

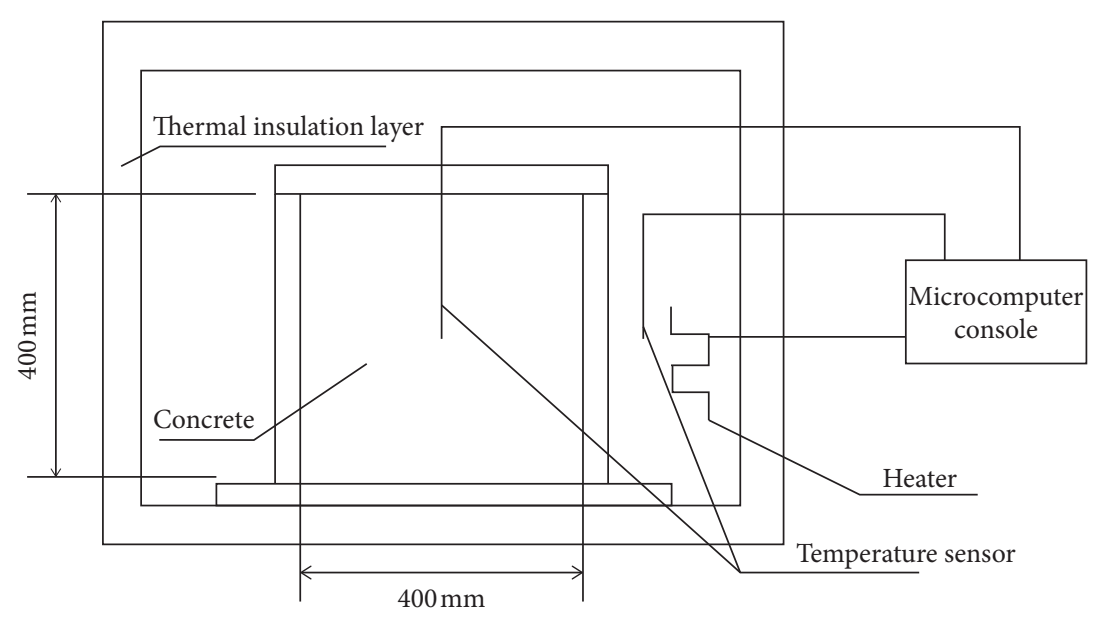

Figure 2: Schematic diagram of IMJR-500 concrete adiabatic temperature rise tester.

in the center of the container and a small amount of transformer oil is put into the tube. Second, insert a temperature sensor into both the tube and adiabatic chamber, cover the container, and close the instrument door as shown in Figure 3(c). Finally, the test was started, and a data acquisition system shown in Figure 3(d) was to collect the data. The temperature of the sample center was recorded every half an hour at the beginning of the test, every 1 hour after 24 hours, and every 5 hours after 7 days. The test lasted 28 days in total.

\subsection{Analysis of Adiabatic Temperature Rise Test Results.} The adiabatic temperature rise curve of the CSG material under different cementing agent content is shown in
Figure 4. It can be seen that the temperature of the CSG material keeps rising due to the heat released during the hydration of the cement. The final adiabatic temperature rises from $6.14^{\circ} \mathrm{C}$ to $23.85^{\circ} \mathrm{C}$ with cementing agent content from $40 \mathrm{~kg} / \mathrm{m}^{3}$ to $140 \mathrm{~kg} / \mathrm{m}^{3}$. The temperature increases about $4^{\circ} \mathrm{C}$ with the increase of cementing agent content of $20 \mathrm{~kg} / \mathrm{m}^{3}$. With the increase of the cementing agent content, the hydration reaction termination time is increased. The adiabatic temperature rise of CSG material with $40 \mathrm{~kg} / \mathrm{m}^{3}$ cementing agent content reached about $95 \%$ of the final adiabatic temperature rise on the fifth day of the test, while it takes fifteen days when $140 \mathrm{~kg} / \mathrm{m}^{3}$ cementing agent content was added. This is mainly due to the large amount of fly ash, which had a delayed effect on the hydration heat of cement. 


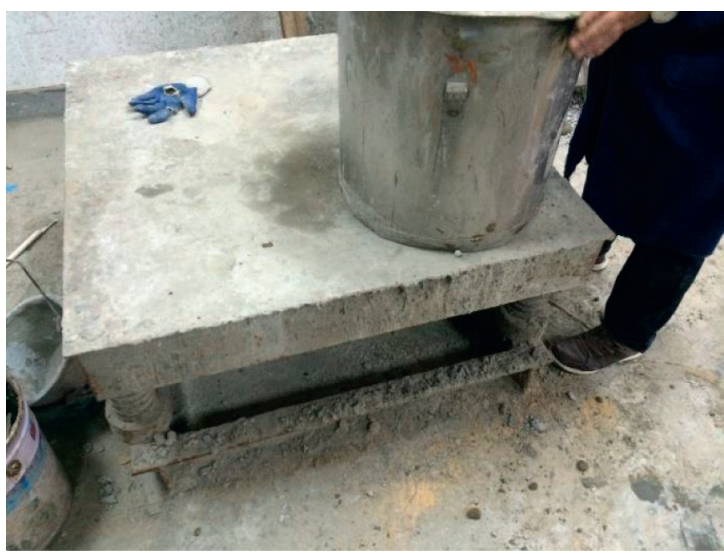

(a)

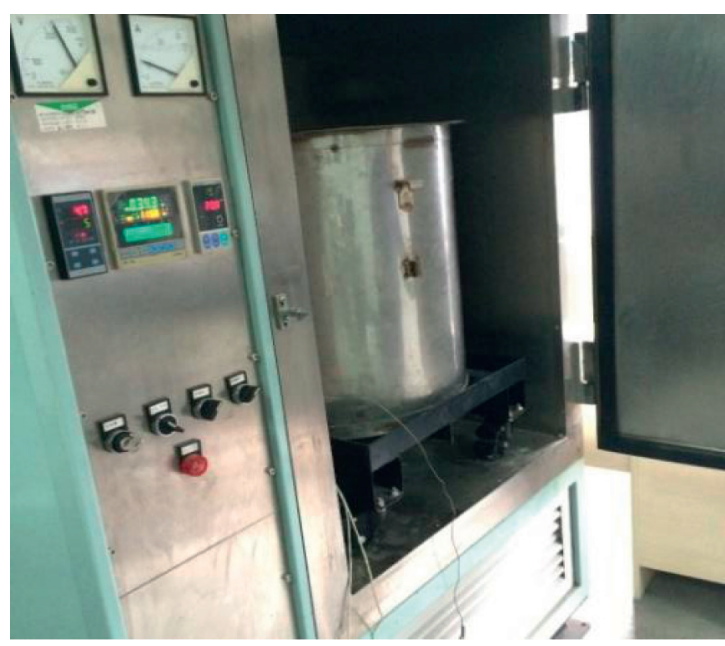

(c)

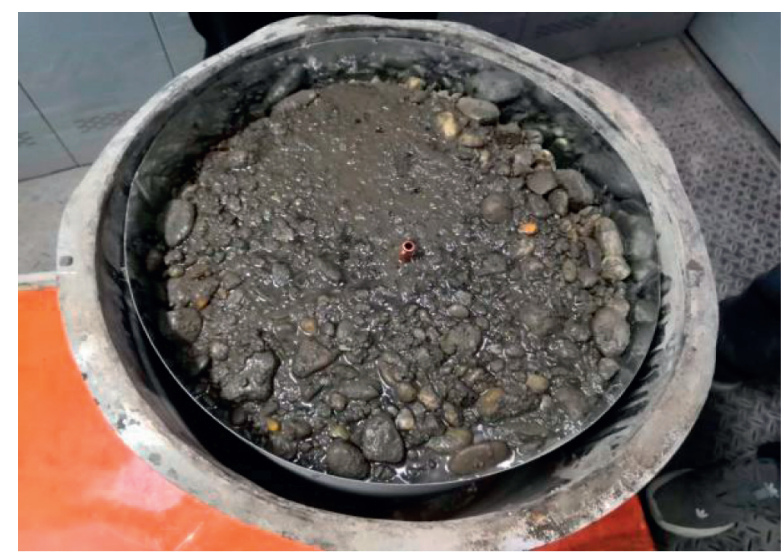

(b)

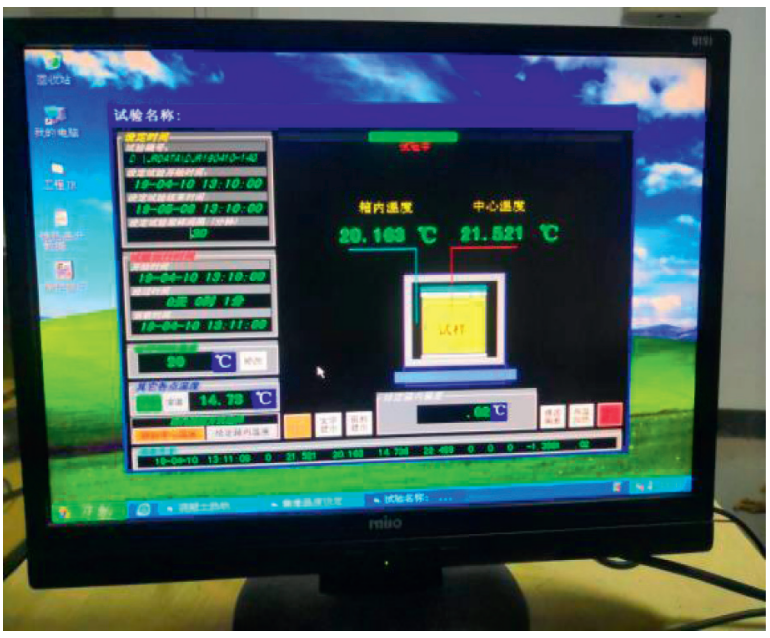

(d)

Figure 3: Sample preparation process. (a) Vibration of CSG material. (b) Insertion of red copper temperature tube. (c) Putting container into adiabatic temperature rise box. (d) Data acquisition system.

Because of the effect of fly ash, the adiabatic temperature rise curve of CSG material still increased slightly at 18th days and remained stable until 24th days. Compared with [12], it can be seen that the hydration reaction rate of CSG material is slower and the reaction time is longer.

The relationship between different cementing agent content and the final value of adiabatic temperature rise is presented in Figure 5. To simplify the analysis, a linear fitting is conducted; the relationship between cementing agent content and the value of final temperature rise is obtained as

$$
\theta_{0}=0.172 \varphi-1.399 \text {, }
$$

where $\theta_{0}$ refers to the final adiabatic temperature rise of CSG material (its unit is ${ }^{\circ} \mathrm{C}$ ) and $\varphi$ is the cementing agent content.

It can be seen from equation (1) that the linear correlation of the formula reaches 0.991 , and the formula can infer the maximum adiabatic temperature rise of CSG material for any cementing agent content.

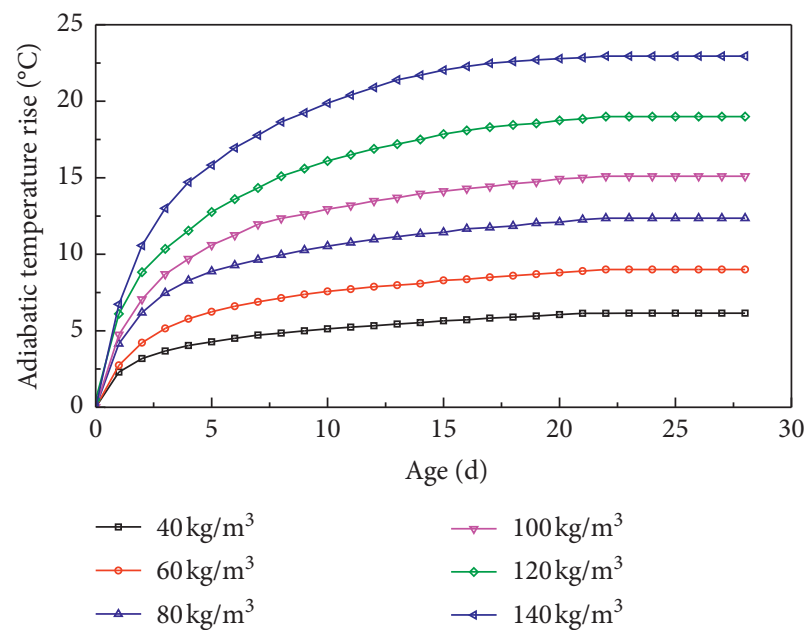

FIgUre 4: Adiabatic temperature rise curve of different cementing agent content. 


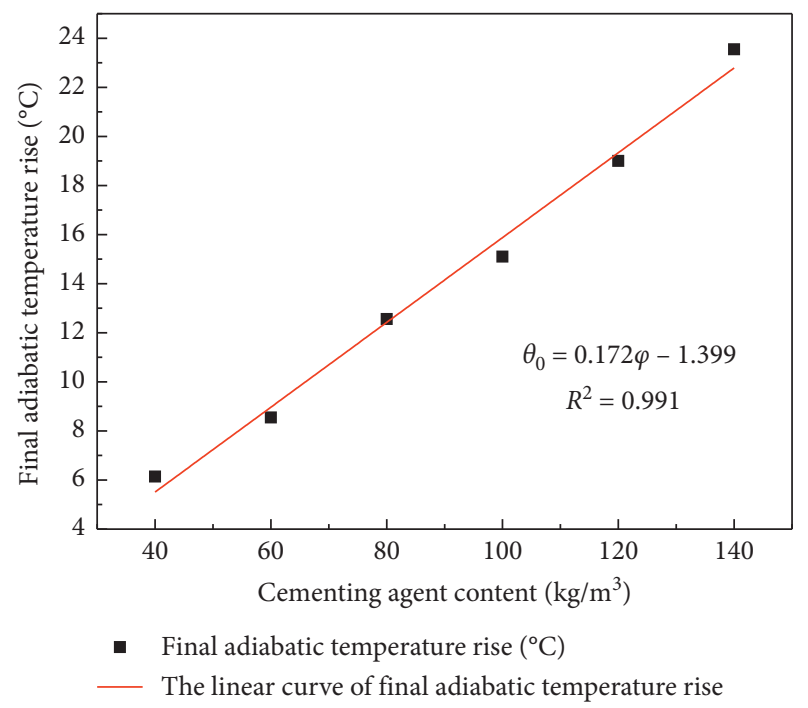

Figure 5: The relationship between cementing agent content and final adiabatic temperature rise.

\section{Calculation Model for Adiabatic Temperature Rise of CSG Material}

Even though the model of adiabatic temperature rise of CSG material can be obtained by cement label and aggregate gradation [29], the adiabatic temperature rise model obtained by this method has some errors due to the large discrete type of CSG material and the difference in material composition from that of ordinary concrete. Another method is to directly fit the experimental data to obtain the adiabatic temperature rise model of CSG material. Zhu [30] proposed two common modes of the adiabatic temperature rise of concrete, that is, hyperbolic function and exponential function, which are shown, respectively, as

$$
\begin{aligned}
& \theta(\tau)=\theta_{0}\left(1-e^{-m \tau}\right), \\
& \theta(\tau)=\frac{\theta_{0} \tau}{(n+\tau)},
\end{aligned}
$$

where $\theta(\tau)$ is the adiabatic temperature rise at age $\tau ; \theta_{0}$ is the final value of adiabatic temperature rise; $m$ and $n$ are the fitting parameters.

Since the composition of CSG material is different from that of ordinary concrete (i.e., the content of fly ash is as high as 50\%), the temperature even rises slightly on the 20th day. For simplicity, the fitting curves of cementing agent content of $40 \mathrm{~kg} / \mathrm{m}^{3}$ and $140 \mathrm{~kg} / \mathrm{m}^{3}$ are depicted in Figure 6. As shown in Figure 6, compared with the exponential adiabatic temperature rise model, the hyperbolic formula can predict the temperature change trend more accurately. Table 3 lists the hyperbolic expressions of cementing agent content from $40 \mathrm{~kg} / \mathrm{m}^{3}$ to $140 \mathrm{~kg} /$ $\mathrm{m}^{3}$. The hyperbolic adiabatic temperature rise model has two parameters $\theta_{0}$ and $n$, among which the parameter $\theta_{0}$ can be obtained through equation (1). It is noted that the parameter $n$ is in the range of 2.6-2.8. This value can be seen as an approximate linear increase with the increase of the cementing agent content, which can be obtained by linear interpolation.

\section{Application to a Typical Dam}

According to the adiabatic temperature rise model obtained in Section 3, Shoukoubu dam [16] located in Shanxi province of China is adopted to analyse its distribution rules of temperature and stress fields based on local climate conditions. It discusses whether the temperature control measures should be considered through comparative analysis.

4.1. Engineering Situation. The total reservoir capacity is 9.8 million $\mathrm{m}^{3}$, which belongs to the category of a small (1) reservoir according to [30]. The crest elevation is $1243.6 \mathrm{~m}$, crest length is $354 \mathrm{~m}$, maximum height is $61.6 \mathrm{~m}$, crest width is $6 \mathrm{~m}$, and the slopes of upstream and downstream dam surface are both $1: 0.6$ [19].

\subsection{Calculation Parameters}

4.2.1. Temperature and Water Temperature Data. The multiyear monthly mean temperature curve of the dam site adopts the cosine function expression proposed by Zhu [29]:

$$
T(\tau)=T_{\mathrm{am}}+A_{a} * \cos \left[\frac{\pi}{6}(\tau-6.5)\right],
$$

where $T(\tau)$ is the monthly average temperature, $\tau$ is the time (unit: month), $T_{\mathrm{am}}$ is the annual average temperature, and $A_{a}$ is the annual variation of temperature.

According to the statistics of local meteorological elements, the annual average temperature in the region is $7.01^{\circ} \mathrm{C}$, with the highest temperature in July. The multiyear monthly average temperature is listed in Table 4.

Based on the data obtained in Table 4, the multiyear monthly average temperature curve of the dam site is expressed as follows:

$$
T(\tau)=7.01+15.57 * \cos \left[\frac{\pi}{6}(\tau-6.5)\right] .
$$

After reservoir impoundment, water temperature can be calculated according to the following formula:

$$
T(y, \tau)=T_{c}(y)+A(y) * \cos \left[\frac{\pi}{6}\left(\tau-\tau_{0}-\varepsilon\right)\right],
$$

where $T(y, \tau)$ refers to the water temperature at a depth of $y$; $T_{c}(y)$ and $A(y)$ refer to the annual mean water temperature and annual variation of water temperature at a depth of $y$, respectively; $\tau_{0}$ refers to the highest temperature in a year; $\varepsilon$ refers to phase difference.

Since this area belongs to north China, the water temperature at the bottom of the reservoir is selected as $6^{\circ} \mathrm{C}$, and the surface temperature of the reservoir is chosen as the air temperature. Then, the water temperature along the depth is obtained:

$$
\begin{aligned}
T(y, \tau)= & 11.37+10.33 e^{-0.04 y}+7.4 e^{-0.018 y} \\
& * \cos \left[\frac{\pi}{6}\left(\tau-2.15+1.3 e^{-0.085 y}\right)\right] .
\end{aligned}
$$




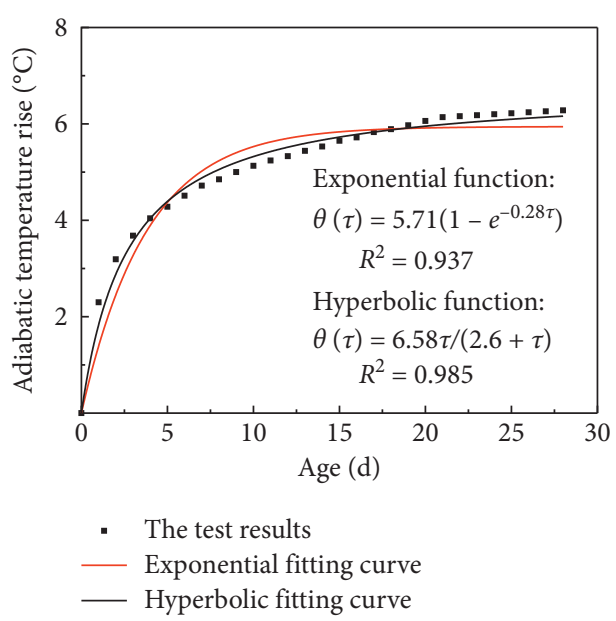

(a)

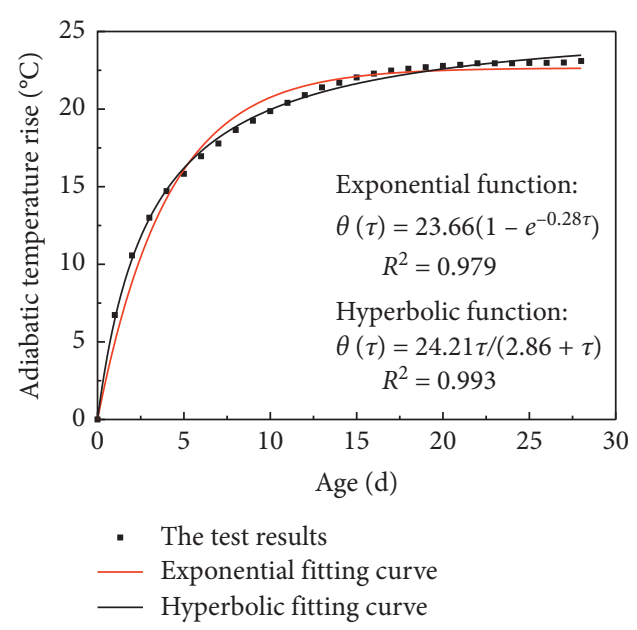

(b)

Figure 6: Adiabatic temperature rise curve fitting with different cementing agent content. (a) $40 \mathrm{~kg} / \mathrm{m}^{3}$. (b) $140 \mathrm{~kg} / \mathrm{m}^{3}$.

TABle 3: Adiabatic temperature rise expression of different cementing agent content.

\begin{tabular}{lc}
\hline Cementing agent content $\left(\mathrm{kg} / \mathrm{m}^{3}\right)$ & The hyperbolic type $\left({ }^{\circ} \mathrm{C}\right)$ \\
\hline 40 & $\theta(\tau)=6.58 \tau /(2.60+\tau)$ \\
60 & $\theta(\tau)=9.59 \tau /(2.63+\tau)$ \\
80 & $\theta(\tau)=13.63 \tau /(2.64+\tau)$ \\
100 & $\theta(\tau)=16.84 \tau /(2.72+\tau)$ \\
120 & $\theta(\tau)=20.58 \tau /(2.79+\tau)$ \\
140 & $\theta(\tau)=24.21 \tau /(2.80+\tau)$ \\
\hline
\end{tabular}

4.2.2. Construction Schedule. The construction of the dam began on July 1, 2015, and ended on July 10, 2016. It is composed of 20 layers, each layer has a height of $3 \mathrm{~m}$, and every layer is constructed over 10 days. Because the reservoir dam is located in the cold zone, construction was stopped from November to April of the following year. That is to say, the construction of the dam was stopped on October 31 , 2015 , when the dam was poured up to 36 meters high. The construction was continued from May 1, 2016, and lasted 380 days in total.

4.2.3. Material Parameters. The material parameters used in the literature [21] are borrowed here. The thermal parameters of CSG material and soil are shown in Table 5, and elastic modulus $E_{\tau}$ and allowable tensile strength $f_{\tau}$ with time are shown, respectively:

$$
\begin{aligned}
& f_{\tau}=1.34 \times\left[1-e^{\left(-0.42 \tau^{0.35}\right)}\right], \\
& E_{\tau}=10.9 \times\left[1-e^{\left(-0.42 \tau^{0.56}\right)}\right] .
\end{aligned}
$$

The cementing agent content is $90 \mathrm{~kg} / \mathrm{m}^{3}$, and the expression of adiabatic temperature rise $\theta_{\tau}$ is calculated through equation (1) and Table 3 as

$$
\theta_{\tau}=\frac{14.08 \tau}{2.68+\tau}
$$

4.2.4. Calculation Model. The section of the dam with a width of 20 meters is considered here. Considering that the CSG material itself is focused on here, the outer impermeable layer and cushion of the dam are not considered. When building the finite element model, the sizes of the bedrock are taken the same as those of the dam height. That is to say, the sizes of the bedrock along the upstream and downstream flow directions are both taken as $60 \mathrm{~m}$. In the finite element model, the $x$-axis is along the flow direction, the $Y$-axis is along the vertical flow direction, and the $z$-axis is along the direction of the height of the dam body. In the numerical simulation of dams, nonlinear models such as Drucker-Prager, Mohr-Coulomb, and Cam-clay [31] are often used. Considering the low stress level [25] of concrete dam and the need of temperature stress calculation, the nonlinear elastic model is adopted for dam body and foundation in this paper. $\mathrm{H}$ type hexahedral linear element was used in the calculation, in which the element Solid 70 was used for temperature field and the element Solid 185 for stress field. In order to simulate the construction progress of the dam, restore the construction process, and take into account the influence of the length width ratio of the grid on the calculation accuracy, a $1 \mathrm{~m}$ thick grid is used in this paper. The finite element mesh is divided by mapping mesh, which makes the mesh more regular and reflects the actual construction situation along the horizontal direction. In addition, the element birth and death technology in ANSYS is used to simulate the rising process of the dam pouring [32]. In the selection of boundary conditions, the bottom of the foundation, four sides, and transverse section of the dam body are adiabatic boundaries when calculating the temperature field. When calculating the stress field, the bottom of the foundation is fixed, normal constraints are attached to the four sides, and the dam body part is a free surface [33-35]. The grid after partition is shown in Figure 7.

\subsection{Results}

4.3.1. Analysis of Temperature Field. The locations of different key points of the dam are shown in Figure 8. The 
TABLE 4: The local monthly mean temperature.

\begin{tabular}{|c|c|c|c|c|c|c|c|c|c|c|c|c|}
\hline Month & 1 & 2 & 3 & 4 & 5 & 6 & 7 & 8 & 9 & 10 & 11 & 12 \\
\hline Temperature $\left({ }^{\circ} \mathrm{C}\right)$ & -10 & -6.6 & 0.5 & 9.2 & 16.1 & 20.2 & 21.6 & 19.6 & 14.5 & 7.8 & -1.1 & -7.6 \\
\hline
\end{tabular}

TABLE 5: The thermodynamic parameters of CSG dam and soil.

\begin{tabular}{lccccc}
\hline Material & $\begin{array}{c}\text { Thermal conductivity } \lambda \\
\left(\mathrm{kJ} /\left(\mathrm{m} \cdot \mathrm{h} \cdot{ }^{\circ} \mathrm{C}\right)\right)\end{array}$ & $\begin{array}{c}\text { Specific heat } c \\
\left(\mathrm{~kJ} /\left(\mathrm{kg} \cdot{ }^{\circ} \mathrm{C}\right)\right)\end{array}$ & $\begin{array}{c}\text { Thermal conductivity } \\
\text { coefficient } a\left(\mathrm{~m}^{2} / \mathrm{h}\right)\end{array}$ & $\begin{array}{c}\text { Parameter coefficient of linear } \\
\text { expansion } \alpha\left(1 /{ }^{\circ} \mathrm{C}\right)\end{array}$ & $\begin{array}{c}\text { Density } \rho \\
\left(\mathrm{kg} / \mathrm{m}^{3}\right)\end{array}$ \\
\hline Foundation & 4.05 & 1.57 & 0.0020 & $0.76 \times 10^{-5}$ \\
CSG & 7.375 & 0.99 & 0.0016 & $0.56 \times 10^{-5}$ & 1802.8 \\
\end{tabular}

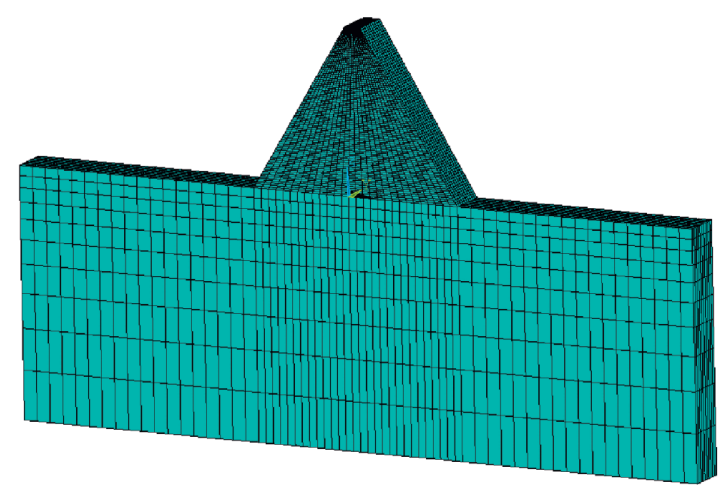

(a)

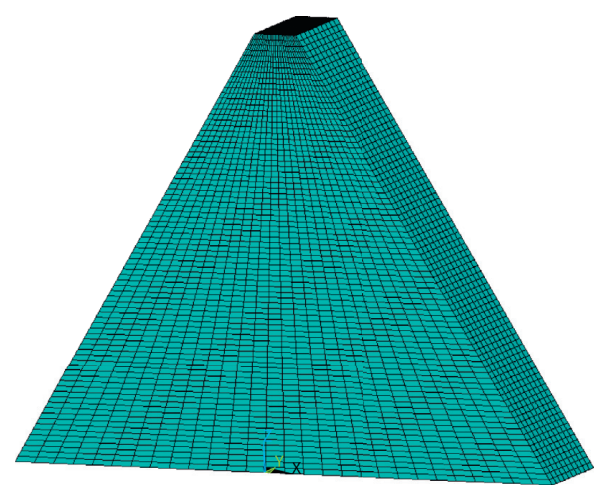

(b)

Figure 7: The mesh of finite element model. (a) The integral calculation model. (b) The dam body calculation model.

temperature distributions during the period of completion of dam construction $(380 \mathrm{~d})$, winter of the third year $(1000 \mathrm{~d})$, severe winter of the sixth year $(2000 \mathrm{~d})$, and summer of the tenth year $(2920 \mathrm{~d})$ are shown in Figure 9 . It can be seen from Figure 9(a) that the temperature field of the dam body is high inside and low outside due to heat release from the hydration of cement and heat dissipation from the dam surface. On October 31,2015 , the dam body was casted to the twelfth layer. As the temperature gradually dropped to $4^{\circ} \mathrm{C}$, the pouring began to stop for 6 months, resulting in the low temperature of the dam body within the height range of $36 \mathrm{~m}$. Therefore, when the dam body is just poured, two high-temperature areas are both formed at the height of $18 \mathrm{~m}$ and top of the dam. As can be seen from Figures 9(b) and 9(c), as the water temperature is higher than the air temperature in winter, the surface temperature of the dam body is significantly higher than that of the exposed air. Due to the lack of thermal insulation measures on the surface of the dam, the exposed surface temperature of the dam varies with the external temperature, and the temperature gradient on the surface of the dam in winter is relatively large. As can be seen from Figure 9(d), due to the low temperature rise of hydration heat, the surface temperature of the CSG dam is higher than that of the center at the later stage of the dam operation. Due to the heat dissipation of the dam body, the maximum temperature dropped from $30.45^{\circ} \mathrm{C}$ at the completion of pouring to $19.44^{\circ} \mathrm{C}$ four years later with an average annual decrease of $3^{\circ} \mathrm{C}$. Although the temperature rise of the CSG dam is not high, the temperature at the center of the dam body still drops slowly as that of RCC. Compared with the results in [36] and Figure 9, it can be observed that the temperature field distribution of CSG dam with high cementing agent content is similar to that of RCC dams.

The temperature duration curve of different horizontal positions at the dam height of $24 \mathrm{~m}$ is shown in Figure 10. It can be seen that the temperatures of surface points of the dam body are greatly affected by the climatic temperature. The closer the dam body is to the internal point, the less the temperature is affected. The maximum temperature difference between $\mathrm{K} 1$ and $\mathrm{K} 4$ reaches $39.4^{\circ} \mathrm{C}$; therefore, thermal insulation measures should be taken on the surface of the dam body in winter.

4.3.2. Analysis of Temperature Stress Field. Based on the results of the temperature field, the stress field distribution law of the CSG dam is analysed. The stress distribution cloud diagram at the same age of the temperature field is shown in Figure 11. The temperature stress duration curve of different horizontal positions at the height of $24 \mathrm{~m}$ dam is shown in Figure 12. Figure 13 shows the curve of temperature stress changing with time at $\mathrm{K} 5$ with different cementing agent contents and insulation thickness.

As can be seen from Figure 11(a), the stress field cloud map presents a relatively obvious stratified distribution due to the stratified construction of the dam. When the dam has just finished pouring in summer, the overall stress field of the 


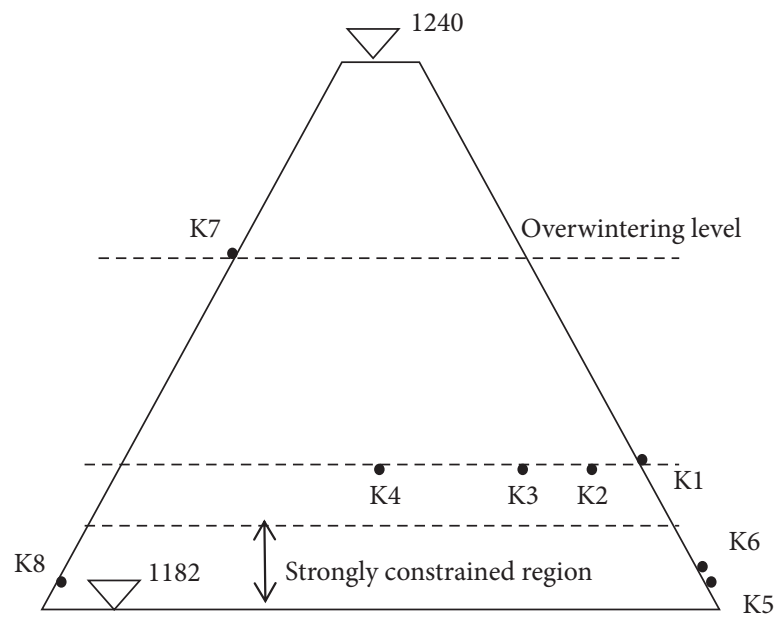

Figure 8: Position diagram of different key points of dam body.

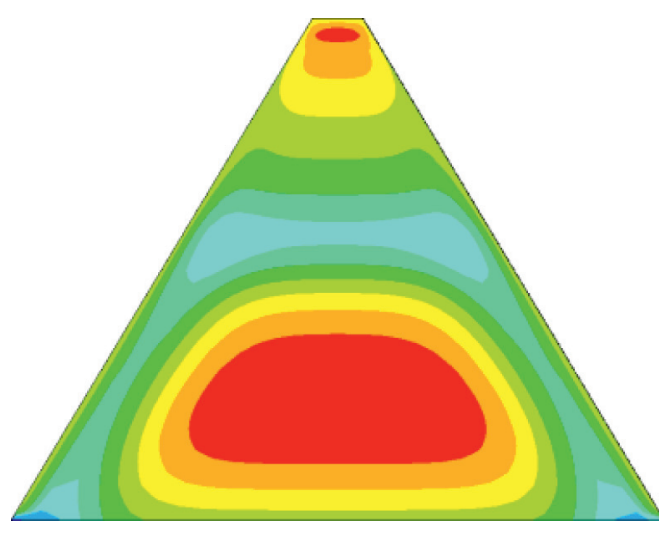

(a)

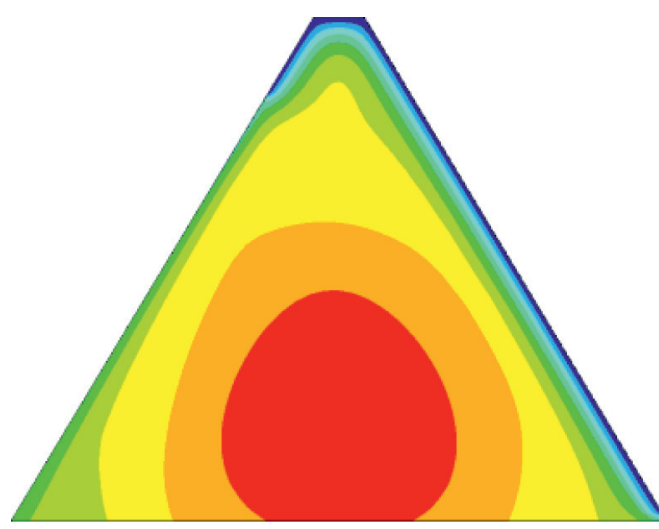

(c)
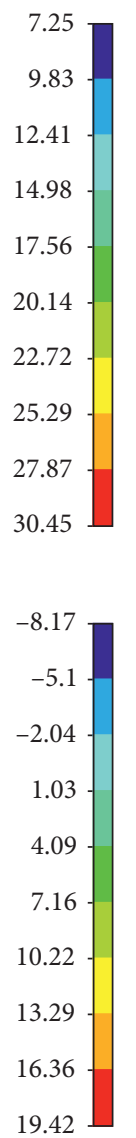

19.42

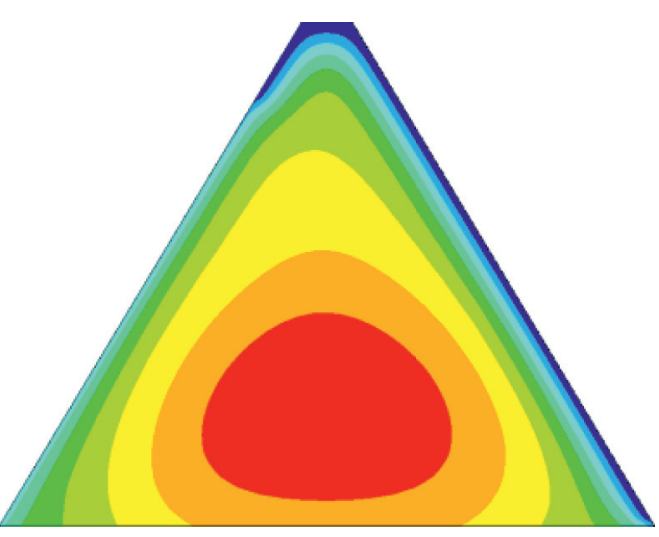

(b)

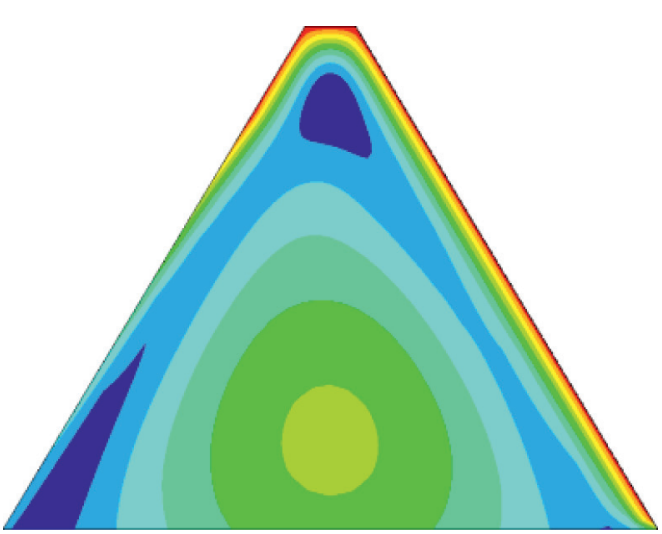

(d) $\left.\begin{array}{r}6.18 \\ 7.98 \\ 9.78 \\ 11.58 \\ 13.38 \\ 15.18 \\ 16.98 \\ 18.78 \\ 20.58 \\ 22.39\end{array}\right]$

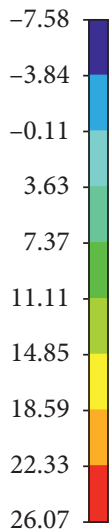

26.07

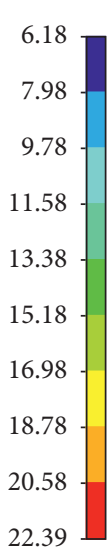

FIGURE 9: Distribution diagram of temperature during construction and operation (unit: ${ }^{\circ} \mathrm{C}$ ). (a) $380 \mathrm{~d}$ ( (b) $1000 \mathrm{~d}$. (c) $2000 \mathrm{~d}$ (d) $2920 \mathrm{~d}$.

dam body presents external pressure and internal tension except the existence of tensile stress at the long intermittent surface. It can be seen from Figures 11(b) and 11(c) that the tensile stress of dam heel and dam site is relatively large in winter, and the closer it is to the bedrock, the greater the tensile stress is, largely because the bedrock belongs to the strong constraint area of dam body. At the same time, the upper part of the long intermittent surface ( $36 \mathrm{~m}$ high) of the dam also produces large tensile stress, but the tensile stress in this area is relatively small compared with those in the dam site. This is mainly due to the high strength of CSG material in the long intermittent surface area after 6 months of 


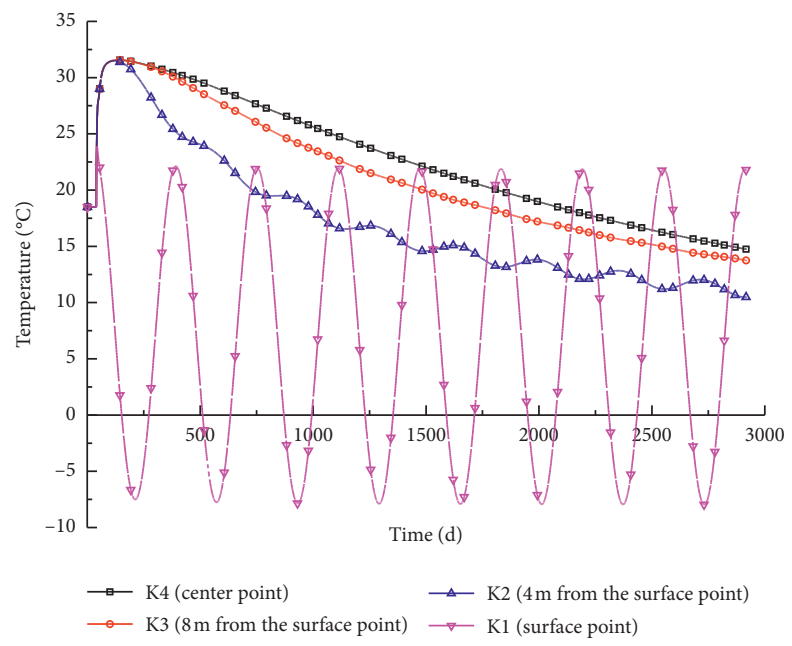

FIgURE 10: The temperature duration curves at different positions of dam height of $24 \mathrm{~m}$.

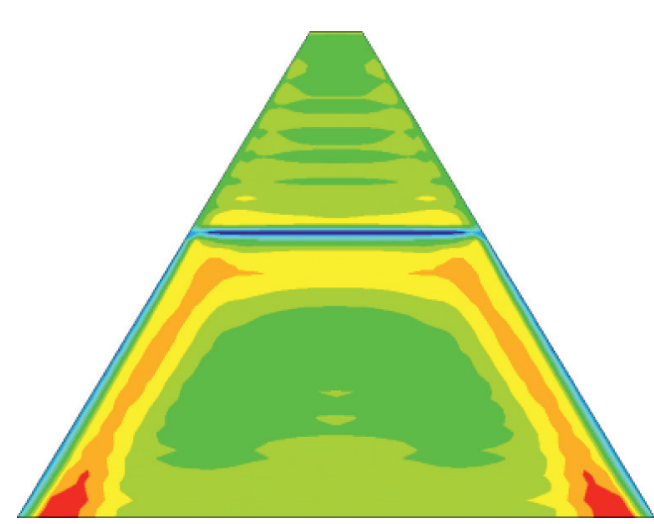

(a)

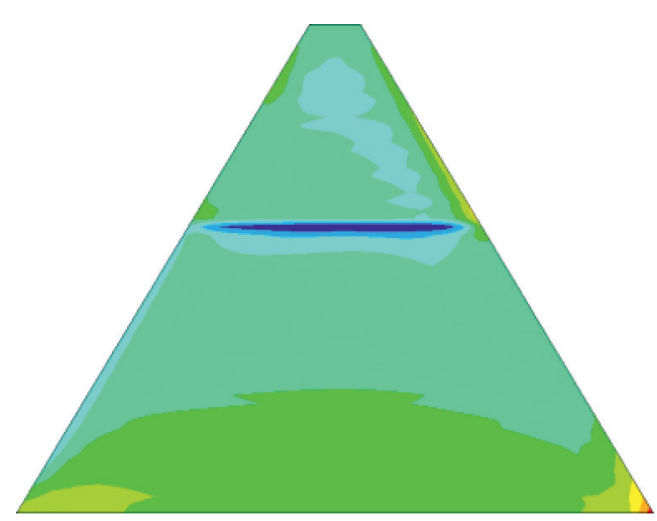

(c)

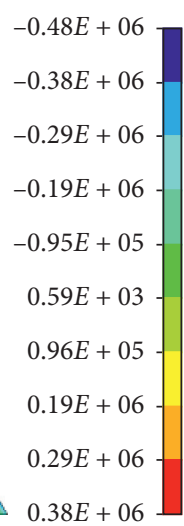

$-0.70 E+06$
$-0.48 E+06$
$-0.26 E+06$
$-0.34 E+05$
$0.19 E+06$
$0.41 E+06$
$0.63 E+06$
$0.85 E+06$
$0.11 E+07$
$0.13 E+07$

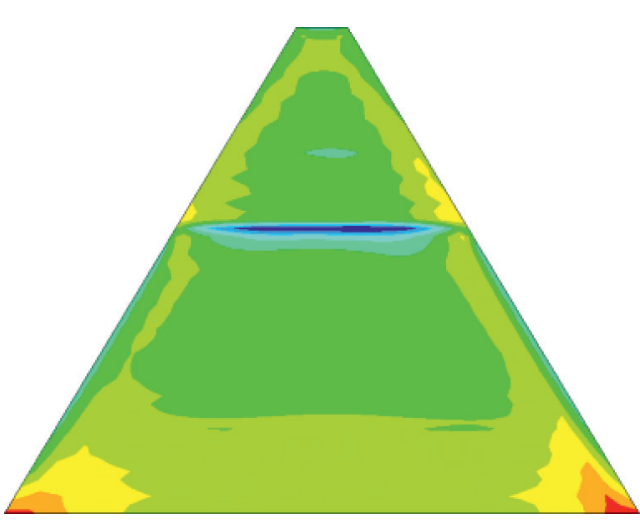

(b)

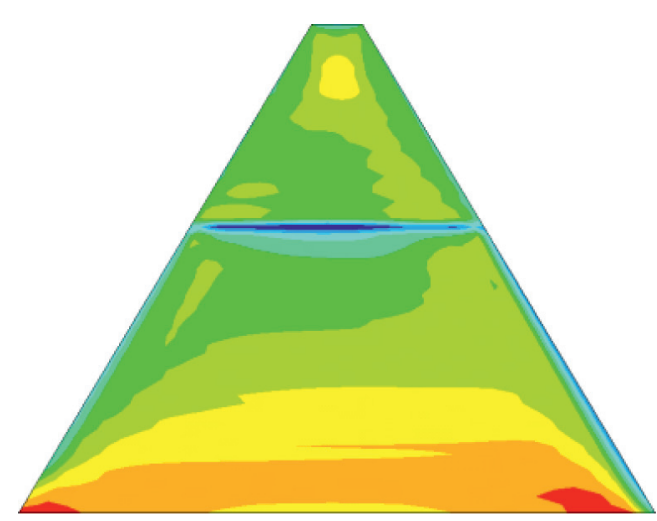

(d)
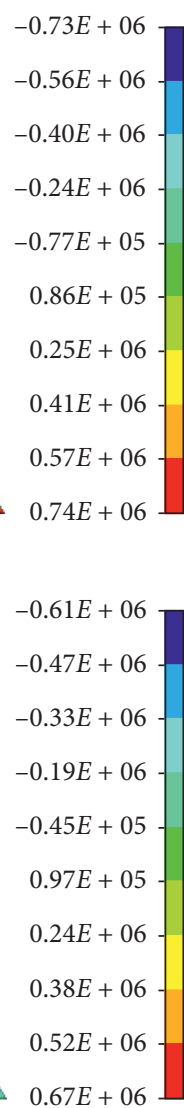

$0.67 E+06$

FIGURE 11: Distribution diagram of temperature stress during construction and operation (unit: Pa). (a) 380 d. (b) 1000 d. (c) 2000 d. (d) 2920 d.

solidification, it forms a strong constraint on the casting of CSG material in the upper layer, and the stress still decreases with the height of the dam. By comparing Figures 11(a) and 11(d), it can be seen that the stress of the dam body is symmetrically distributed before water storage, and the tensile stress of the downstream region of the dam body is greater than that of the upstream region after water storage. The main reason is that the temperature difference between the center of the dam body and the upstream dam face is smaller, which is caused by the fact that the water 


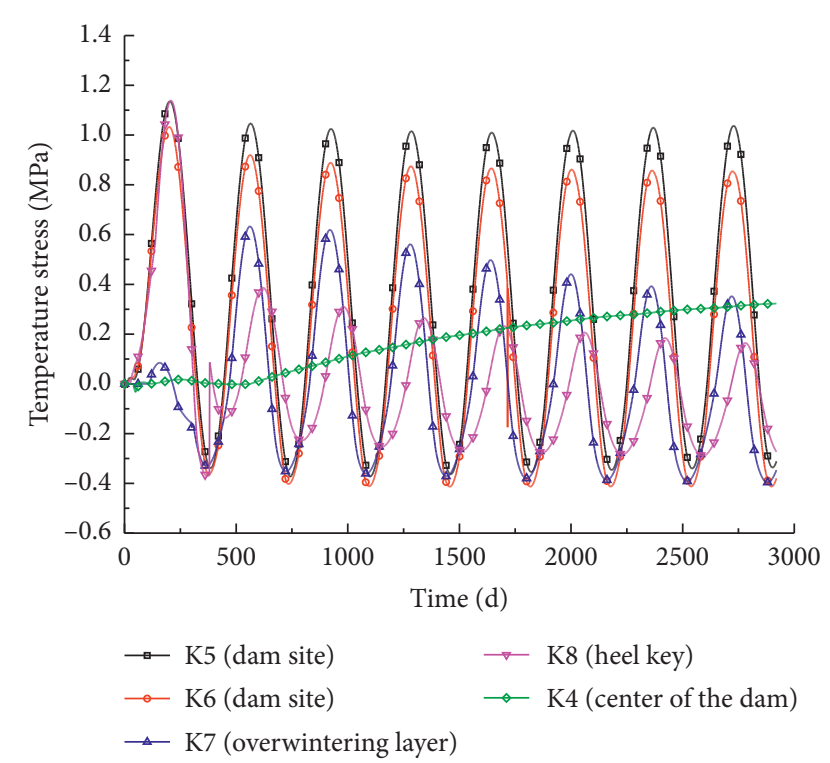

Figure 12: Temperature stress duration curves of different key point of dam body.

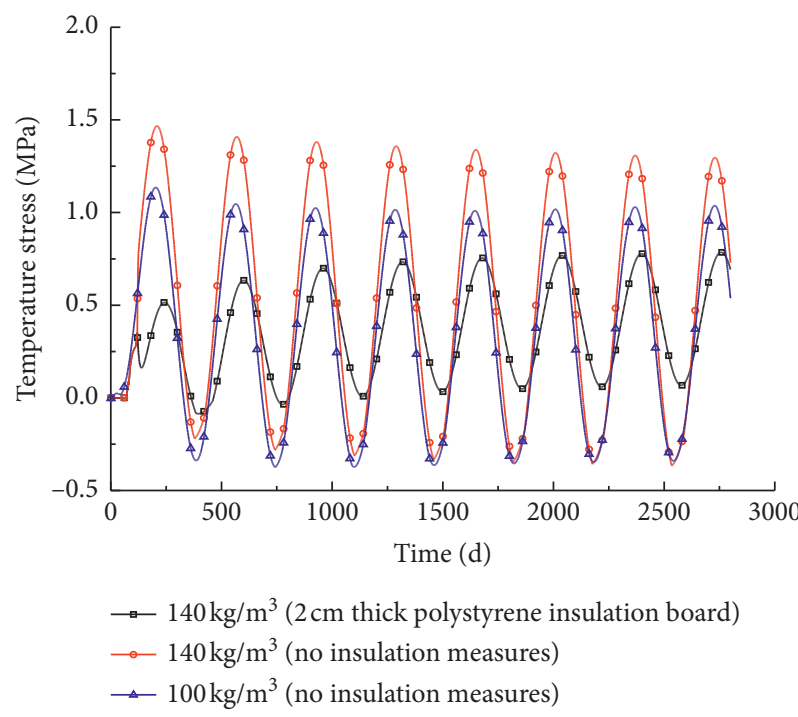

Figure 13: Temperature stress duration curves at K5 under different conditions.

temperature change range is lower than that of the temperature. Therefore, it is necessary to focus on the distribution of tensile stress in the downstream of the dam body after water storage. In general, the stress distribution of CSG dams is similar to that of RCC dams. The tensile stress near the dam site is still the focus area, but the stress value is smaller than that of RCC dams.

As can be observed in Figure 12, the stress at the surface point $\mathrm{K} 5$ is greatly affected by climate temperature and presents a periodic change, while the stress inside the dam body presents a slow growth trend. By comparing the stresses in $\mathrm{K} 5, \mathrm{~K} 6$, and $\mathrm{K} 7$, it can be seen that the tensile stress decreases as the constraint of the dam foundation decreases along the direction of the elevation of the dam. The stress at key point K8 under the water surface changes periodically with the water temperature, and the tensile stress is relatively small compared to those at K5 and K6.

According to Figure 13, when the cementing agent content is $100 \mathrm{~kg} / \mathrm{m}^{3}$ without consideration of the surface insulation measures, the surface tensile stress during the first winter at the dam site (K5) reached $1.15 \mathrm{MPa}$, which approaches the allowable tensile strength. When the cementing agent content reached $140 \mathrm{~kg} / \mathrm{m}^{3}$, the maximum tensile stress at the dam site (K5) reaches $1.5 \mathrm{MPa}$, which has exceeded the allowable tensile strength, and there is a risk of cracking. When $2 \mathrm{~cm}$ thick polystyrene insulation board is considered, the tensile stress on the surface drops to $0.6 \mathrm{MPa}$, and the insulation effect is obvious. Some researchers and engineers believe that temperature control measures need not be considered in the construction of CSG dams. In this paper, temperature control and crack prevention of 60 meter-high CSG dam in northwest China are studied, but there are still many conditions not considered. For example, the climate of different areas, the thickness of dam construction layer, dam height, dam joints, and so on all have an impact on the selection of dam temperature control and crack prevention measures. Therefore, it cannot be generalized that the CSG dam did not need to consider temperature control measures, and it was determined according to the actual situation. At present, simple temperature control measures should be taken into account when building dams in cold areas with high cementing agent content.

\section{Conclusion}

In this study, the adiabatic temperature rise test is conducted for CSG material with different cementing agent contents, and a suitable adiabatic temperature rise model is proposed. The numerical simulation analysis of a dam model is performed, and the following conclusions are drawn:

(1) When the cementing agent content becomes higher, the termination time of the adiabatic temperature rise reaction is longer. The final value of the adiabatic temperature rise exhibits a linear growth relationship with the cementing agent content.

(2) Compared with the exponential formula, the hyperbolic formula provides a better fitting result for the adiabatic temperature rise curve of CSG materials. The formula for the adiabatic temperature rise curve for different cementing agent contents provides accurate results for future engineering simulations.

(3) The overall temperature of the dam body is high inside and low outside, and the thermal insulation measures can effectively reduce the temperature difference between inside and outside. The temperature of the CSG dam is low at the overwintering level, and thermal insulation materials need to be covered in winter. The temperature of the CSG dam rises with the increase of cementing agent content, 
and it is close to that of an RCC dam when the cementing agent content is high.

(4) The CSG dam with a poured long intermittent surface as well as downstream surface produces a large surface tensile stress, and the tensile stresses can be reduced significantly if insulation measures are adopted. Thus, temperature control measures must be considered in the construction of CSG dams that have a high cementing agent content and are located in cold regions.

\section{Data Availability}

The data used to support the findings of this study are included in the article.

\section{Conflicts of Interest}

The authors declare that there are no conflicts of interest regarding the publication of this paper.

\section{Acknowledgments}

The authors would like to acknowledge the support by the National Key Research and Development Program during the 13th Five-Year Plan Period (2018YFC0406804), the National Natural Science Foundation projects (no. 51979094), and the National Science and Technology Pillar Program during the 12th Five-Year Plan Period (2012BAD10B02).

\section{References}

[1] J. M. Raphael, "The Optimum Gravity Dam," Rapid Construction of Concrete Dams, ASCE, New York, NY, USA, 1970.

[2] P. Londe and M. Lino, "The faced symmetrical hardfill dam: a new concept for RCC," International Water PowereDam Construction, vol. 44, no. 2, pp. 19-24, 1992.

[3] J. Chen, X. Cai, E. Lale, J. Yang, and G. Cusatis, "Centrifuge modeling testing and multiscale analysis of cemented sand and gravel (CSG) dams," Construction and Building Materials, vol. 223, pp. 605-615, 2019.

[4] X. Cai, J. Yang, and X. W. Guo, "Review of cement sand and gravel dams," Journal of Hohai University (Natural Sciences), vol. 43, no. 5, pp. 431-441, 2015.

[5] X. Cai, Y. Wu, X. Guo, and Y. Ming, "Research review of the cement sand and gravel (CSG) dam," Frontiers of Structural and Civil Engineering, vol. 6, no. 1, pp. 19-24, 2012.

[6] Y. H. Han, S. J. Fu, S. F. Wang, and Z. W. Xie, "Study on adiabatic temperature rise reflecting hydration degree of concrete," Advances in Materials Science and Engineering, vol. 2018, Article ID 1435049, 12 pages, 2018.

[7] Y. Y. Huang, "Optimization of temperature-control measures for concrete structures: a case study of the sluice project," Advances in Civil Engineering, vol. 2018, Article ID 4823130, 8 pages, 2018.

[8] Z. H. Wang, L. Tao, Y. Liu, and Y. H. Jiang, “Temperature control measures and temperature stress of mass concrete during construction period in high-altitude regions," $A d-$ vances in Civil Engineering, vol. 2018, Article ID 9249382, 12 pages, 2018.
[9] L. Li, X. H. Liu, V. TN. Dao, and Y. G. Cheng, "Thermal cracking analysis during pipe cooling of mass concrete using particle flow code," Advances in Materials Science and Engineering, vol. 2016, Article ID 5976862, 10 pages, 2016.

[10] R. Luna and Y. Wu, "Simulation of temperature and stress fields during RCC dam construction," Journal of Construction Engineering and Management, vol. 126, no. 5, pp. 381-388, 2000.

[11] Y. Y. Huang and Z. Y. Wan, "Study on viscoelastic deformation monitoring index of an RCC gravity dam in an alpine region using orthogonal test design," Mathematical Problems in Engineering, vol. 2018, Article ID 8743505, 12 pages, 2018.

[12] X. F. Zhang, Q. Liu, X. Zhang, Y. L. Li, and X. P. Wang, “A study on adiabatic temperature rise test and temperature stress simulation of rock-fill concrete," Mathematical Problems in Engineering, vol. 2018, Article ID 3964926, 12 pages, 2018.

[13] T. Hirose, T. Fujisawa, and H. Yoshida, "Concept of CSG and its material properties," in Proceedings 4th International Symposium on Roller Compacted Concrete Dams, pp. 465-473, Madrid, Spain, 2003.

[14] T. N. Lohani, L. Kongsukprasert, K. Watanabe, and F. Tatsuoka, "Strength and deformation properties of compacted cement-mixed gravel evaluated by triaxial compression tests," Soils and Foundations, vol. 44, no. 5, pp. 95-108, 2004.

[15] S. M. Haeri, A. Hamidi, S. M. Hosseini, E. Asghari, and D. G. Toll, "Effect of cement type on the mechanical behavior of a gravely sand," Geotechnical and Geological Engineering, vol. 24, no. 2, pp. 335-360, 2006.

[16] J. Jia, M. Lino, F. Jin, and C. Zheng, "The cemented material dam: a new, environmentally friendly type of dam," Engineering, vol. 2, no. 4, pp. 490-497, 2016.

[17] M. Kondo, T. Sasaki, and H. Kawasaki, "Characteristics of stress distribution in trapezoid-shaped csg dam during earthquake," in Proceedings of the 13th World Conference on Earthquake Engineering, Vancouver, Canada, pp. 33-92, 2004.

[18] SL 678-2014, Technical Guideline for Cemented Granular Material Dams Particles, Ministry of Water Resources of the People's Republic of China, Beijing, China, 2014.

[19] J. S. Jia, N. Liu, C. Y. Zheng, F. L. Ma, Z. K. Du, and Y. Wang, "Research progress and engineering application of cemented granular dam," Journal of Water Conservancy, vol. 47, no. 3, pp. 315-323, 2016.

[20] M. Q. Sun, Study on the Mechanical Properties, Durability and Dam Type of Cement Sand and Gravel Material, China Water Conservancy and Hydropower Press, Beijing, China, 2016.

[21] M. Q. Sun and L. Guo, Study on Mechanical Properties, Durability and Dam Type of Gelled Gravel Materials, North China university of water resources and hydropower, Zhengzhou, China, 2016.

[22] L. Guo, Y. J. Duan, and M. Q. Sun, “Adiabatic temperature rise model of CSG materials and its application," Yellow River, vol. 38, no. 7, pp. 89-91, 2016.

[23] Z. W. Liu, Research on Material Property of Cemented Material Dam, china institute of Water Resources \& Hydropower Research, Beijing, China, 2018.

[24] Y. L. He, Y. F. Peng, and K. Xiong, "Analysis on material property of Hardfill dam," Journal of Water Resources and Architectural Engineering, vol. 5, no. 4, pp. 1-6, 2007.

[25] Y. L. He and Y. F. Peng, "Analysis of structural characteristics of Hardfill dam," Journal of Hydroelectricity, vol. 27, no. 6, pp. 68-72, 2009. 
[26] S. Wang, Quality control and reliability analysis in the whole process of CSG dam, Ph.D. thesis, China Institute of Water Resources \& Hydropower Research, Beijing, China, 2019.

[27] A. F. Gurdil, "Batmaz, structural design of clidere dam," in Proceedings 4th International Symposium on Roller Compacted Concrete Dams, RCC Compacted concrete Dams, Madrid, Spain, pp. 312-318, 2003.

[28] H. L. Wu, Y. F. Peng, and Y. Yuan, "Study on simplified construction temperature control measures of CSG dam," Water Resources and Hydropower Technology, vol. 45, no. 1, pp. 76-84, 2015.

[29] B. F. Zhu, Thermal Stresses and Temperature Control of Mass Concrete, Butterworth-Heinemann, Oxford, UK, 2016.

[30] DL5180-2003, Classification and Design Safety Standard of Hydropower Projects, State Economic and Trade Commission of the People's Republic of China, Beijing, China, 2003.

[31] M. Karalar and M. Cavusli, "Seismic effects of epicenter distance of earthquake on 3D damage performance of CG dams," Earthquakes and Structures, vol. 18, no. 2, pp. 201-213, 2020.

[32] A. Gaspar, F. Lopez-Caballero, A. Modaressi-FarahmandRazavi, and A. Gomes-Correia, "Methodology for a probabilistic analysis of an RCC gravity dam construction. Modelling of temperature, hydration degree and ageing degree fields," Engineering Structures, vol. 65, pp. 99-110, 2014.

[33] A. I. H. Malkawi, S. A. Mutasher, and T. J. Qiu, "Thermalstructural modeling and temperature control of roller compacted concrete gravity dam," Journal of Performance of Constructed Facilities, vol. 17, no. 4, pp. 177-187, 2003.

[34] L. Zhang, Y. Liu, B. Q. Li, and G. X. Zhang, "Study on realtime simulation analysis and inverse analysis system for temperature and stress of concrete dam," Mathematical Problems in Engineering, vol. 2015, Article ID 306165, 8 pages, 2015.

[35] J. Zhang, C. Huang, C. Lu, L. Han, P. Wang, and G. Li, "Automatic thermal analysis of gravity dams with fast boundary face method," Engineering Analysis with Boundary Elements, vol. 41, pp. 111-121, 2014.

[36] Z. Si, L. Z. Huang, and S. Y. Li, Temperature Control Simulation and Crack Prevention of RCC Dams in Severe Cold Areas, China Electric Power Press, Beijing, China, 2018. 